\title{
Enzymatic reduction of azo and indigoid compounds
}

\author{
S. Pricelius • C. Held • M. Murkovic • M. Bozic • \\ V. Kokol • A. Cavaco-Paulo • G. M. Guebitz
}

Received: 3 May 2007 / Revised: 10 August 2007 / Accepted: 15 August 2007 / Published online: 22 September 2007

(C) Springer-Verlag 2007

\begin{abstract}
A customer- and environment-friendly method for the decolorization azo dyes was developed. Azoreductases could be used both to bleach hair dyed with azo dyes and to reduce dyes in vat dyeing of textiles. A new reduced nicotinamide adenine dinucleotide-dependent azoreductase of Bacillus cereus, which showed high potential for reduction of these dyes, was purified using a combination of ammonium sulfate precipitation and chromatography and had a molecular mass of $21.5 \mathrm{kDa}$. The optimum $\mathrm{pH}$ of the azoreductase depended on the substrate and was within the range of $\mathrm{pH} 6$ to 7 , while the maximum temperature was reached at $40^{\circ} \mathrm{C}$. Oxygen was shown to be an alternative electron acceptor to azo compounds and must therefore be excluded during enzymatic dye reduction. Biotransformation of the azo dyes Flame Orange and Ruby Red was studied in more detail using UV-visible spectroscopy, high-performance liquid chromatography, and mass spectrometry (MS). Re-
\end{abstract}

S. Pricelius · C. Held · G. M. Guebitz $(\bowtie)$

Department of Environmental Biotechnology,

Graz University of Technology,

Petersgasse 12,

8010 Graz, Austria

e-mail: guebitz@tugraz.at

M. Murkovic

Department of Food Chemistry and Technology,

Graz University of Technology,

Petersgasse 12,

8010 Graz, Austria

M. Bozic $\cdot$ V. Kokol

Department of Textiles, University of Maribor,

Maribor, Slovenia

A. Cavaco-Paulo

Department of Textile Engineering, University of Minho,

Braga, Portugal duction of the azo bonds leads to cleavage of the dyes resulting in the cleavage product 2-amino-1,3 dimethylimidazolium and $N \sim 1 \sim, N \sim 1 \sim$-dimethyl-1,4-benzenediamine for Ruby Red, while only the first was detected for Flame Orange because of MS instability of the expected 1,4benzenediamine. The azoreductase was also found to reduce vat dyes like Indigo Carmine (C.I. Acid Blue 74). Hydrogen peroxide $\left(\mathrm{H}_{2} \mathrm{O}_{2}\right)$ as an oxidizing agent was used to reoxidize the dye into the initial form. The reduction and oxidation mechanism of Indigo Carmine was studied using UV-visible spectroscopy.

Keywords Azo reductase $\cdot$ Hairdye $\cdot$ Flame orange $\cdot$ Indigo · Bacillus cereus

\section{Introduction}

Azo dyes are used as components in permanent hair dyes. Additionally, azo compounds represent the largest class of dyes applied in the textile, food, and cosmetic industry (Stolz 2001). Azo dyes used as components in permanent hair dyes can only be decolorized by drastic methods such as chemical bleaching using, for example, hydrogen peroxide. However, this treatment can cause hair damage and may cause health problems (Kleinszanto and Slaga 1982). Hence, the use of these methods requires extreme precautions to prevent these adverse effects. Therefore, it would be highly desirable to develop a customer-friendly and safe treatment avoiding the use of hazardous chemicals. Enzymes that specifically oxidize or reduce azo bonds and thereby decolorize dyed hair could be an elegant alternative. Enzymes can be used under mild conditions, and they do not have negative effects on hair and skin. 
Besides azo dyes, redox (vat) dyes occupy a significant place in the dyeing of textile fabrics such as denim. Vat dyes are insoluble in water but can be reduced, in the presence of a reducing agent in an alkaline medium, to form a water-soluble dye known as the leuko-compound. The most commonly used reducing agent in vat dyeing is sodium dithionite. However, one of the major drawbacks of this industrial dyeing process is the high amount of sulfate, sulfite, and thiosulfate in the wastewater and of the toxic sulfide formed subsequently by bio-corrosion of the wastewater pipelines.

Again, our research efforts are focused on the replacement of sodium dithionite by an enzymatic reduction of redox dyes.

Azo and vat dyes are quite resistant to aerobic biological degradation (Zollinger 1987); nevertheless, decolorization in aerobic, anaerobic, anoxic, or combined treatment processes have been reported (Banat et al. 1996; Bragger et al. 1997; Rafii et al. 1990; Wuhrmann et al. 1980). Microorganisms produce enzymes that reductively cleave the azo bond at the expense of a reducing agent, typically $\mathrm{NAD}(\mathrm{P}) \mathrm{H}$. The occurrence of these so-called azoreductases has been reported for various bacteria.

Recently, we have shown that azoreductases can reduce a large structural variety of systematically substituted azo dyes, while oxidases (laccases, MnP) seem to have less potential for this purpose (Maier at al. 2004; Pricelius et al. 2007). The nonspecificity of the azoreductase reaction was also demonstrated by many reports on the decolourization of azo dyes by sewage sludge under anaerobic conditions (Carliell et al. 1994; Moutaouakkil et al. 2003; Zollinger 1987). It seems that almost all azo compounds tested are biologically reduced under anaerobic conditions, although there are some indications that metal-ion-containing dyes sometimes have reduced decolorization rates (Chung and Stevens 1993). Cell extracts show usually much higher rates for anaerobic reduction of azo dyes than preparations of resting cells (Wuhrmann et al. 1980). This has generally been explained by the low permeability of the cell membranes for the azo compounds (Russ et al. 2000).
In this paper, we report for the first time that a purified azoreductase from Bacillus cereus was capable of reducing Indigo Carmine. Additionally, hair dyes Flame Orange and Ruby Red were chosen for this study because these dyes are used in many cosmetic products on the market.

\section{Materials and methods}

\section{Chemicals and enzymes}

The azo dyes Flame Orange and Ruby Red were supplied from CIBA Sc and are used as components in permanent hair dyes (Fig. 1). Indigo Carmine (Fig. 1) was supplied from Fluka and is used in food, cosmetics, and pharmacy. All other chemicals used were analytical grade and purchased from Sigma. B. cereus was kindly provided from F. Sousa (Sousa et al. 2007).

For the production of azoreductase, B. cereus was cultivated for $12 \mathrm{~h}$ in 1-1 baffled Erlenmeyer flasks on a rotary shaker at $160 \mathrm{rpm}$ and $38^{\circ} \mathrm{C}$ in $500 \mathrm{ml}$ standard I nutrient medium (Merck). Cells were harvested by centrifugation for $15 \mathrm{~min}$ at $3,000 \times \mathrm{g}$, and the pellet was resuspended in $50 \mathrm{mM}$ sodium phosphate buffer, $\mathrm{pH} 7.0$ ( $2 \mathrm{ml}$ buffer per gram of wet cell paste $/ 45 \mathrm{~g}$ total yield). Cell lysis was done with a French press (American Instrument, Maryland, USA), performing three passes. The cell debris was removed by centrifugation at $34,000 \times \mathrm{g}$ for $60 \mathrm{~min}$ at $4^{\circ} \mathrm{C}$, and the supernatant was filtered through a prefilter (Glass Fiber Filter with binder, AP20, $75 \mathrm{~mm}$, Millipore, Billerica, USA), a $45-\mu \mathrm{m}$ filter with pressure filtration, and through a Minisart single-use syringe filter sterile EO using a $0.2-\mu \mathrm{m}$ membrane (Sartorius, Hannover, Germany).

Assay for azoreductase activity

Assays were carried out in cuvettes with a total volume of $1 \mathrm{ml}$. One unit of enzyme activity was defined as the amount of enzyme that transformed $1 \mu \mathrm{mol}$ of substrate<smiles>[NH3+][Os](=O)(=O)c1ccc2c(c1)C(=O)/C(=C1/Nc3ccc(S(=O)(=O)[OH+])cc3C1=O)N2</smiles><smiles>Cn1cc[n+](C)c1/N=N/c1ccc(N)cc1</smiles>

Flame Orange<smiles>CN(C)c1ccc(/N=N/c2n(C)cc[n+]2C)cc1</smiles>

Ruby Red

Fig. 1 Chemical structure Flame Orange, Ruby Red, and Indigo Carmine 
per minute. The reaction mixture contained $400 \mu \mathrm{l}$ of $50 \mathrm{mM}$ sodium phosphate buffer ( $\mathrm{pH} 7.0), 200 \mu \mathrm{l}$ of the sample, and $200 \mu \mathrm{l}$ of the azo dye Cibacrone Marine (C.I. Reactive Black 5; $100 \mathrm{mg} \mathrm{l}^{-1}$ ). The reaction was initiated by the addition of $200 \mu \mathrm{l}$ reduced nicotinamide adenine dinucleotide (NADH; $7.09 \mathrm{mg} \mathrm{ml}^{-1}$, final concentration $2 \mathrm{mM}$ ) and followed spectrophotometrically at $595 \mathrm{~nm}$. The slope of the initial linear decrease of absorption was used to calculate the enzyme activity based on the molar absorption coefficient of Cibacrone Marine $\left(\varepsilon_{595}=35.5 \mathrm{mmol}^{-1} \mathrm{~cm}^{-1}\right)$ as described previously (Maier et al. 2004).

$\mathrm{pH}$ and temperature optima and stability of the azoreductase

For determination of the $\mathrm{pH}$ dependence of azoreductase, $50 \mathrm{mM}$ succinate buffer was adjusted to $\mathrm{pH} 3.0$ to 5.0, $50 \mathrm{mM}$ sodium phosphate buffer was set to $\mathrm{pH}$ values of 6.0 and 7.0, and for $\mathrm{pH} 8.0$ up to 11 , a $50-\mathrm{mM}$ borate buffer was used. NADH solution and dyestuff solution were prepared with the corresponding buffers. Samples were incubated for $5 \mathrm{~min}$, and adding NADH started the reaction. For the determination of the temperature optimum, all solutions were brought to the corresponding temperature before mixing, and the spectrophotometer was temperature controlled during measurement.

\section{Protein purification}

The cell lysate of $B$. cereus was subjected to fractionated ammonium sulfate precipitation at $40 \%$ saturation to remove impurities, followed by $60 \%$ saturation in a second step to precipitate the azoreductase. The precipitated proteins from the second precipitation step were collected by centrifugation, and the pellet was dissolved in $30 \mathrm{ml}$ of phosphate buffer $(50 \mathrm{mM}, \mathrm{pH} 7.0)$. The solution was desalted by dialysis against phosphate buffer $(50 \mathrm{mM}$, $\mathrm{pH}$ 7.0) overnight. The desalted solution after ammonium sulfate precipitation was filtrated trough a $0.45-\mu \mathrm{m}$ filter, and $1.5 \mathrm{ml}$ aliquots of the resulting solution were applied to a HiTrap Q FF column (Amersham Biosciences) installed in an Amersham pharmacia biotech ÄKTA purifier 900; Pump P903; Monitor pH/Cond-900; Monitor UV-900; Autosampler Frac-900 (Amersham Biosciences Europe GmbH, Vienna, Austria). Proteins were eluted at $1 \mathrm{ml} \mathrm{min}^{-1}$ with the sample buffer and with a stepwise-increasing concentration of buffer containing $1 \mathrm{M} \mathrm{NaCl}$. Azoreductase-active fractions were pooled and applied to the same column a second time. The active fractions were collected and stored as the purified enzyme preparation. The protein content of samples was measured by using the Bradford dye-binding assay (Coomassie blue; Bio-Rad) according to the protocols of the manufacturers and using bovine serum albumin as the standard.

\section{Gel electrophoresis}

Polyacrylamide gel electrophoresis (PAGE) was carried out as described previously (Sousa et al. 2007), with some modifications for native PAGE, i.e., both the detergent component sodium dodecyl sulfate (SDS) and 2-mercaptoethanol ( $\beta$-mercaptoethanol) were omitted. Twelve percent polyacrylamide gels were utilized, and broad-range molecular weight markers from Pharmacia were used as standards. For activity staining, the method of Maier et al. (2004) was used. The gel was immediately immersed in approximately $50 \mathrm{ml}$ of $50 \mu \mathrm{M}$ Reactive Black 5 solution for $25 \mathrm{~min}$. After removal of the staining solution, the gel was put into a desiccator and a vacuum was applied. Afterward, the desiccator was filled with $\mathrm{N}_{2}$, and a degassed NADH solution ( $2 \mathrm{mM} \mathrm{NADH}$ in $50 \mathrm{mM}$ phosphate buffer, $\mathrm{pH}$ 7.0) was added under the $\mathrm{N}_{2}$ atmosphere. To make sure that no oxygen remained in the test vessel, vacuum generation and $\mathrm{N}_{2}$ scavenging were repeated alternately several times. Bands of the active enzyme appeared after approximately $10 \mathrm{~min}$ as white spots within a blue background.

\section{Dye biotransformation studies}

Biotransformation of Flame Orange, Ruby Red and Indigo Carmine was carried out in cuvettes containing $1 \mathrm{U} \mathrm{ml}^{-1}$ azoreductase of crude cell extract from $B$. cereus and the purified enzyme, $200 \mathrm{\mu g} \mathrm{ml}^{-1}$ dye, $7 \mathrm{mM}$ NADH in $50 \mathrm{mM}$ sodium phosphate buffer $(\mathrm{pH}$ 7.0). Decolorization was monitored at $\lambda_{\max }$ of the dyes. Controls were run without addition of enzymes.

High-performance liquid chromatography and mass spectrometry analysis

Dye degradation products of Flame Orange and Ruby Red were separated with an high-performance liquid chromatography (HPLC) system equipped with a RP18 column (Amersham Biosciences Europe $\mathrm{GmbH}$ ) with acetonitrile and $15 \mathrm{mM} \mathrm{H}_{3} \mathrm{PO}_{4}, 10 \mathrm{mM} \mathrm{H}_{2} \mathrm{SO}_{4}$, and distilled water as the mobile phase at a flow rate of $1 \mathrm{ml} \mathrm{min}^{-1}$ at $40^{\circ} \mathrm{C}$. Water was distilled twice and filtered through a $0.45-\mu \mathrm{m}$ Millipore filter and degassed before use.

A Dionex HPLC system (Dionex, Sunnyvale, CA) consisting of a P580 pump, ASI-100 automated sample injector, and a PDA-100 photodiode array detector was used with the following operating conditions: injection volume, $10 \mu \mathrm{l}$, and column temperature, $40^{\circ} \mathrm{C}$; detection wavelength was chosen according to the absorbance 
maxima for the azo dyes (Flame Orange $=486 \mathrm{~nm}$; Ruby Red $=526 \mathrm{~nm}$ in addition at 210, 220, and $300 \mathrm{~nm}$ ). The mobile phase was a degassed mixture of $\mathrm{A}$, double distilled water, and $\mathrm{B}$, acetonitrile, under isocratic conditions ranging from 8 to $25 \%$ depending on the dye.

For the detection of degradation products of Flame Orange after reductase treatment, the mobile phase consisted of $\mathrm{B}, 14 \%, 10 \mathrm{mM} \mathrm{H}_{2} \mathrm{SO}_{4}, 50 \%$, and $36 \%$ of mobile phase A. For the degradation products of Ruby Red, the mobile phases were $\mathrm{B}, 25 \%, 10 \mathrm{mM} \mathrm{H}_{2} \mathrm{SO}_{4}, 30 \%$, and $\mathrm{A}, 45 \%$.

The mass spectrometry (MS) analysis was done on an Agilent MSD (Waldbronn, Germany) with direct injection using the following parameters: Drying gas temperature $350^{\circ} \mathrm{C}$, drying gas pressure $40 \mathrm{psi}$, drying gas flow (nitrogen) $101 \mathrm{~min}^{-1}$, capillary voltage $3,500 \mathrm{~V}$, fragmentor voltage $70 \mathrm{~V}$, mass range 70 to $400 \mathrm{~m} / \mathrm{z}$. The data were analyzed using the software Chemstation Rev. A 10.01 (Agilent). For measurement in the positive mode, $0.01 \%$ acetic acid was added. To check for fragments formed during the MS, the fragmentor voltage was set from 25 to $150 \mathrm{~V}$.

\section{Results}

\section{Purification of the azoreductase}

For the purification of the B. cereus azoreductase, in the first step, the cell lysate was subjected to fractionated ammonium sulfate precipitation at 40 and $60 \%$ saturation. The sample resulting from precipitation had an activity of $8.45 \mathrm{U} \mathrm{ml}^{-1}$ and $120 \mathrm{mg}$ of protein. The resulting solution was desalted by repeated ultrafiltration and was fractionated twice by anion-exchange chromatography with a HiTrap Q FF. During this procedure, the specific azoreductase activity based on protein increased from $0.03 \mathrm{U} \mathrm{mg}^{-1}$ in the lysate to $0.67 \mathrm{U} \mathrm{mg}^{-1}$ for the purified enzyme with an amount of $0.03 \mathrm{mg}$ of protein. The azoreductase had a molecular mass of $21.5 \mathrm{kDa}$ as determined by SDS-PAGE. Numerous attempts to use the zymogram assay from described previously (Maier et al. 2004) with the purified azoreductase of B. cereus failed. Unfortunately, only crude cell lysate and semipurified samples (desalted sample after ammonium sulfate precipitation) showed activity in the native gel (Fig. 2). This can be ascribed to the partial inactivation of azoreductase during anion exchange chromatography and the resulting low activity recovery.

The $\mathrm{pH}$ optimum of the azoreductase was determined with cibracrone marine by measuring the activity within the range of $\mathrm{pH}$ values 5.0 to 9.0, and an optimum was found at $\mathrm{pH}$ 7.0. The azoreductase activity increased almost linearly in the temperature range from 20 to $30^{\circ} \mathrm{C}$ reaching its optimum at $40^{\circ} \mathrm{C}$.
Fig. 2 Zymogramm of the semipurified azoreductases (lane 1) and cell lysate from $B$. cereus (lane 2). The white bands on the zymogram gel indicate azoreductase activity. Band 2 corresponds to the purified $21.5 \mathrm{kDa}$ azoreductase as determined by SDS-PAGE (12.5\%)

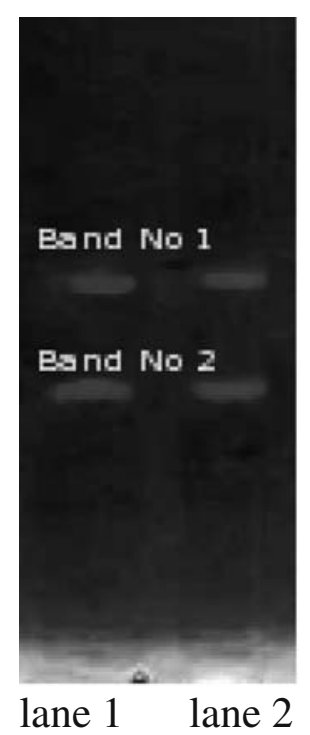

UV-Vis absorbance spectrometry and mass spectrometry

Our studies have demonstrated that Ruby Red and Flame Orange were completely decolorized by azoreductase prepared from B. cereus (Fig. 3). Complete decolorization of Flame Orange and Ruby Red by Bacillus-derived azoreductases lead to several highly polar transformation products with a retention time of less than $1 \mathrm{~min}$ on HPLC. The faster-eluting intermediates absorbed in the UV region. The chromatographic peaks of several target compounds overlapped, but the gradient program could not be optimized in such a way that it was possible to analyze intermediates in detail. The peaks corresponding to Flame Orange and Ruby Red disappeared completely indicating full conversion of the azo dyes under the experimental conditions (incubation for 15 min with the azoreductase from B. cereus).

\section{Mass spectrometry}

To exclude the possibility of dye degradation during MS analysis, standards of Ruby Red and Flame Orange were analyzed as well.

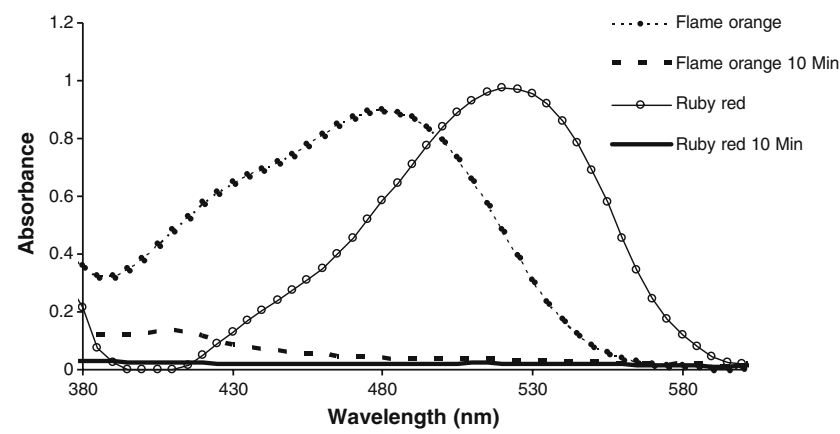

Fig. 3 Decolorization of Flame Orange and Ruby Red with azoreductase of $B$. cereus 
Reduction of azo compounds by azoreductases from $B$. cereus should lead to the corresponding aromatic amines (Maier et al. 2004). Indeed, the mass spectra of the reduction products indicated reduction of Ruby Red to the corresponding amines, $N \sim 1 \sim, N \sim 1 \sim$-dimethyl-1,4benzenediamine with a molecular mass of 136 and 2amino-1,3 dimethylimidazolium with a mass of 112 . When Ruby Red was treated with azoreductases, a decrease in the compounds with the $\mathrm{m} / z$ of 148 and 244 (the original dye) was observed with increasing incubation time (samples taken at 5, 10, 20, $30 \mathrm{~s}$ ). Concomitantly, an increase in the $\mathrm{m} / \mathrm{z}$ of 112,122 , and 136 was seen. No other significant peak was found in the mass spectra of any of the two dyes tested, i.e., that no by-product was formed in significant concentrations during the reaction.

When Flame Orange was treated with azoreductases, only an increase in the compound with the $\mathrm{m} / \mathrm{z}$ of 112 ascribed to 2-amino-1,3 dimethylimidazolium was seen in the course of the experiment, while the amount of the degradation product $\mathrm{m} / \mathrm{z} 216$ (the original dye) decreased concomitantly. The expected compound with the $\mathrm{m} / \mathrm{z} 108$ (1,4-benzenediamine) was not detected. However, as demonstrated by using a standard of 1,4-benzenediamine, this compound is not stable under the experimental conditions (MS), and several coupling reactions could have taken place.

\section{Indigo Carmine}

The reduction of Indigo Carmine with sodium dithionite was followed spectrophotometrically. After $1 \mathrm{~h}$, Indigo Carmine was oxidized back with the addition of $50 \mu \mathrm{l}$ of $\mathrm{H}_{2} \mathrm{O}_{2}(35 \%$; see Fig. 4).

As shown in Fig. 5, Indigo Carmine could be reduced with the azoreductase from $B$. cereus. This reaction was depended on NADH. The addition of $\mathrm{H}_{2} \mathrm{O}_{2}$, which is used in vat dyeing (vat, Indigo, and sulfur dyes) lead to the reoxidation of the dye after $1 \mathrm{~h}$.

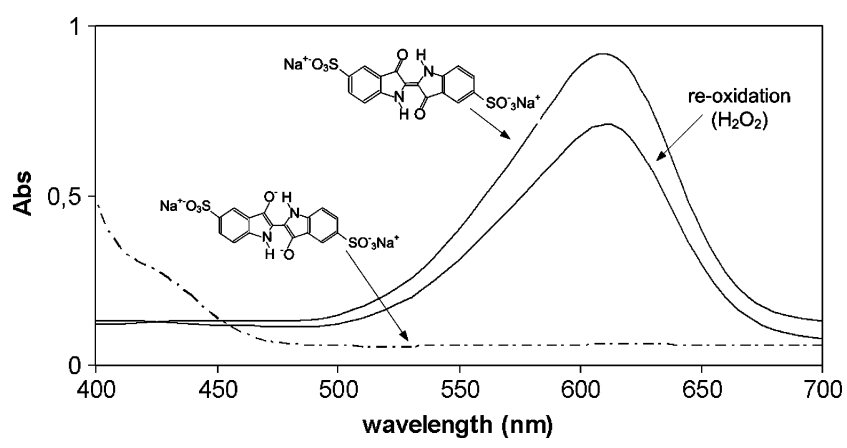

Fig. 4 Wavelength scan of Indigo Carmine using $\mathrm{Na}_{2} \mathrm{~S}_{2} \mathrm{O}_{4}$ for the reduction and $\mathrm{H}_{2} \mathrm{O}_{2}$ for the reoxidation

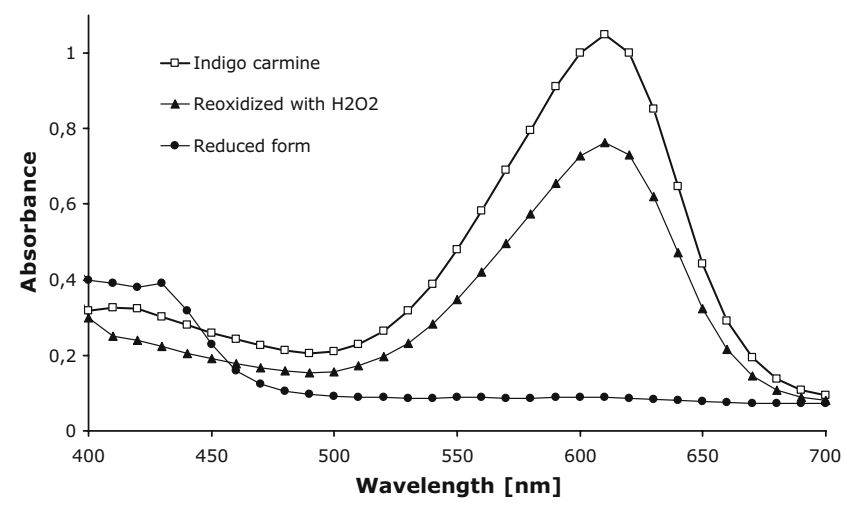

Fig. 5 Reduction of Indigo Carmine with the azoreductase of B. cereus

\section{Discussion}

A new azoreductase was isolated from $B$. cereus that decolorized a number of azo dyes. Two bands showing azoreductase activity were found after separation of the cell lysate in gels combined with activity staining under an oxygen-free atmosphere. Similarly, multiple azoreductases have been previously reported for the alkalothermophilic Bacillus SF (Maier et al. 2004) and also for B. subtilis where a knockout strain of the $y h d \mathrm{~A}$ azoreductase still showed activity.

In general, azoreductase activity could be increased in the absence of oxygen. This biphasic reduction of dyes is in agreement with previous studies (Maier et al. 2004) and is due to the fact that dioxygen can serve as an alternative electron acceptor. Chung et al. mentioned a direct influence of oxygen on the degradation rates of azo dyes by Pseudomonas luteola, although they did not measure any influence with the crude cell extract. However, it is almost not possible to compare activity values from the literature because most studies are based on the decolorization of different dyes.

The azoreductase from B. cereus was purified by a combination of ammonium sulfate precipitation and anionexchange chromatography. Other authors have described the application of affinity chromatography for the purification of azoreductase (Moutaouakkil et al. 2003). The molecular mass of the azoreductase from $B$. cereus was determined to be $21.5 \mathrm{kDa}$. Previously, molecular masses of 21 and $30 \mathrm{kDa}$ were reported for azoreductases from Pseudomonas sp. (Zimmermann et al. 1982), and a mass of $28 \mathrm{kDa}$ was reported for the azoreductase from Enterobacter agglomerans (Moutaouakkil et al. 2003). Temperature optima for azoreductases from $B$ subtilis reported in the literature range from 40 to $45^{\circ} \mathrm{C}$ ( $\mathrm{Hu} 2001$; Matsudomi et al. 1977). Similarly, in this work, the azoreductase from B. cereus showed a temperature optimum at $40^{\circ} \mathrm{C}$ with a $\mathrm{pH}$ optimum at $\mathrm{pH} 7$. 
We have demonstrated that biotransformation of the azo hair dyes Flame Orange and Ruby Red can be achieved by this reductase. Several previous studies have shown that the initial step in the biodegradation of azo dyes under anaerobic conditions is a reductive cleavage of the azo bond at the expense of NADH or NADPH serving as electron donors for the reaction. This process is catalyzed by soluble cytosolic enzymes with low substrate specificity known as azoreductases. Molecular oxygen competes for the available reducing equivalents with the azo dyes and slows down the reductive cleavage of the azo bond. As previously shown for other azo dyedegrading microorganisms, decolorization of the azo dyes Ruby Red and Flame Orange only occurred in the presence of NADH or NADPH as a cosubstrate. When Ruby Red was used as a target structure for reductive cleavage, 2-amino-1,3 dimethylimidazolium and $N \sim 1 \sim$, $N \sim 1 \sim$-dimethyl-1,4-benzenediamine could be detected by MS upon treatment with the purified azoreductase. This clearly demonstrates that azo bond cleavage occurs in the presence of an azoreductase. In the case of Flame Orange, however, the products expected from reductive cleavage could not be observed probably because of auto-oxidation of the 1,4-benzenediamine as previously suggested.

When the azoreductase was incubated with Indigo Carmine, a color change from blue to yellow indicating the reduction of the vat dye could be observed. This reaction was slower than the reduction with chemical reducing agents and required the presence of NADH. Nevertheless, the redox potential of the azoreductase reaches a level of $-500 \mathrm{mV}$ with the addition of NADH and could even be further decreased with other redox mediators. Thus, there is a high potential to reduce various vat dyes with this enzyme.

Concluding our results, we propose that the azoreductase from $B$. cereus decolorizes azo dyes by cleaving the azo bond leading to the free amines, while it is also able to reduce Indigo Carmine to its leuko-form. Under anoxic conditions, this enzyme facilitates the transfer of electrons via NADH to the azo dye, which is then reduced. The reduction rate decreased when methyl groups as electrondonating substituents were introduced into the dye, like in Ruby Red, but the reaction pathway was the same. Thus, earlier results obtained by Zimmermann et al. $(1982,1984)$ were confirmed that decolorization of azo dyes with azoreductases can be enhanced with electron-withdrawing groups at the aromatic ring, especially ortho-substitutions, which show this effect. Furthermore, it was reported that substrates with an electron-negative substituent at the phenyl ring would enhance the enzyme reaction rate. This effect may be due to the fact that electron-withdrawing groups lead to a decreased electron density at the $\mathrm{N}=\mathrm{N}$ double bond. Hence, electron transfer to this group is released.

Summarizing our results, we have demonstrated the potential of an azoreductase from $B$. cereus for the reduction of azo and Indigoid compounds. Further studies toward industrial application should focus on heterologous expression of this enzyme in well-established hosts such as $B$. subtilis as well as the use of well-established commercial systems (e.g., formate dehydrogenase) for cofactor recycling.

Acknowledgments We would like to thank Dr. Kai Uwe-Schöning from CIBA Sc for numerous fruitful discussions and for the initiation of this project.

\section{References}

Banat IM, Nigam P, Singh D, Marchant R (1996) Microbial decolourization of textile-dye-containing effluents: a review. Bioresour Technol 58:217-227

Bragger JL, Lloyd AW, Soozandehfar SH, Bloomfield SF, Marriot C, Martin GP (1997) Investigations into the azo reducing activity of a common colonic microorganism. Int J Pharm 157:61-71

Carliell CM, Barclay SJ, Naidoo N, Buckley CA, Mulholland DA, Senior E (1994) Anaerobic decolorisation of reactive dyes in conventional sewage-treatment processes. Water SA 20:341-344

Chung KT, Stevens SE (1993) Degradation of azo dyes by environmental microorganism and helminthes. Environ Toxicol Chem 12:2121-2132

$\mathrm{Hu}$ TL (2001) Kinetics of azoreductase and assessment of toxicity of metabolic products from azo dyes by Pseudomonas luteola. Water Sci Technol 43:261-269

Kleinszanto AJP, Slaga TJ (1982) Effects of peroxides on rodent skin-epidermal hyperplasia and tumor promotion. J Invest Dermatol 79:30-34

Maier J, Kandelbauer A, Erlacher A, Cavaco-Paulo A, Gubitz GM (2004) A new alkali-thermostable azoreductase from Bacillus sp strain SF. Appl Environ Microbiol 70:837-844

Matsudomi N, Kobayashi K, Akuta S (1977) Purification and some properties of new coccine (NC)-reductase from Bacillus cereus T105 strain. Agric Biol Chem 41(12):2323-2329

Moutaouakkil A, Zeroual Y, Dzayri FZ, Talbi M, Lee K, Blaghen M (2003) Purification and partial characterization of azoreductase from Enterobacter agglomerans. Arch of Biochem Biophys 413:139-146

Pricelius S, Held C, Sollner S, Deller S, Murkovic M, Ullrich R, Hofrichter M, Cavaco-Paulo A, Macheroux P, Guebitz GM (2007) Enzymatic reduction and oxidation of fibre-bound azo-dyes. Enzyme Microb Technol 40:1732-1738

Rafii F, Franklin W, Cerniglia CE (1990) Azoreductase activity of anaerobic bacteria isolated from human intestinal microflora. Appl Environ Microbiol 56:2146-2151

Russ R, Rau J, Stolz A (2000) The function of cytoplasmic flavin reductases in the reduction of azo dyes by bacteria. Appl Environ Microbiol 66:1429-1434

Sousa F, Jus S, Erbel A, Kokol V, Cavaco-Paulo A, Gubitz GM (2007) A novel metalloprotease from Bacillus cereus for protein fibre processing. Enzyme Microb Technol 40:1772-1781

Stolz A (2001) Basic and applied aspects in the microbial degradation of azo dyes. Appl Microbiol Biotechnol 56:69-80 
Wuhrmann K, Mechsner K, Kappeler T (1980) Investigation on ratedetermining factors in the microbial reduction of azo dyes. Eur $\mathrm{J}$ Appl Microbiol Biotechnol 9:325-338

Zimmermann T, Kulla HG, Leisinger T (1982) Properties of purified Orange II azoreductase, the enzyme initiating azo dye degradation by Pseudomonas KF46. Eur J Biochem 129:197-203
Zimmermann T, Gasser F, Kulla HG, Leisinger T (1984) Comparison of two bacterial azoreductases acquired during adaptation to growth on azo dyes. Arch Microbiol 138:37-43

Zollinger H (1987) Colour chemistry syntheses, porperties and applications of organic dyes and pigments. Wiley-VCH, Weinheim 